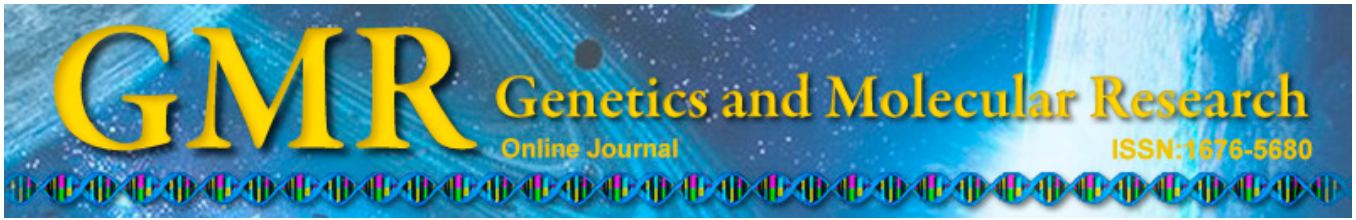

\title{
Related factors and prevalence of Parkinson's disease among Uygur residents in Hetian, Xinjiang Uygur Autonomous Region
}

\author{
X.L. Yang ${ }^{1 *}$, Q. Luo ${ }^{1 *}$, H.X. Song ${ }^{2}$, Y.L. Wang ${ }^{3}$, Y.N. Yao ${ }^{3}$ and H. Xia ${ }^{1}$ \\ ${ }^{1}$ Department of General Medicine, \\ The Third Affiliated Hospital to Xinjiang Medical University, Urumqi, \\ Xinjiang Uyghur Autonomous Region, China \\ ${ }^{2}$ Department of The Third of Internal Medicine-Neurology, \\ The First Hospital of Shijiazhuang City, Shijiazhuang, Hebei Province, China \\ ${ }^{3}$ Department of VIP Integrated Medicine, \\ The First Affiliated Hospital to Xinjiang Medical University, Urumqi, \\ Xinjiang Uyghur Autonomous Region, China \\ *These authors contributed equally to this study. \\ Corresponding author: X.L. Yang \\ E-mail: poplar862@sohu.com
}

Genet. Mol. Res. 14 (3): 8539-8546 (2015)

Received February 27, 2015

Accepted March 31, 2015

Published July 31, 2015

DOI http://dx.doi.org/10.4238/2015.July.31.1

\begin{abstract}
The aim of this study was to identify the factors related to and determine the prevalence of Parkinson's disease (PD) among Uygur residents in Hetian Prefecture, Xinjiang Uygur Autonomous Region. This population-based prospective cohort study used structured questionnaires to screen for factors related to PD. The prevalence in different age groups was analyzed, and PD risk was assessed using univariate and multivariate conditional logistic regression analysis. In total, 5932 subjects participated in the survey; of these, 88 individuals, all of whom were Uygurs, had PD. The overall prevalence of $\mathrm{PD}$ was $1.48 \%(1.32 \%)$ in people over the age of
\end{abstract}


45; the prevalence was $1.68 \%(1.59 \%)$ in men and $1.28 \%(1.36 \%)$ in women. The Fifth Population Census in China found the prevalence of PD in Hetian, Xinjiang, to be $1.32 \%$. Single-factor results showed that exercise, social activities, and frequent consumption of nuts are protective factors for $\mathrm{PD}$, and long-term pesticide exposure, family history of PD, and consumption of barbecued food were risk factors for this condition. Multi-factor conditional logistic regression analysis showed that participation in sports and social activities can reduce the risk of $\mathrm{PD}$, whereas long-term pesticide exposure and family history of PD increases this risk. These results show that PD is caused by the interaction of several factors.

Key words: Parkinson's disease (PD); Prevalence of PD; Risk factors; Case-control study

\section{INTRODUCTION}

Parkinson's disease (PD) is a chronic neurodegenerative disorder affecting older individuals. Its pooled prevalence and incidence were reported to be 2 per 100,000 people and 797 per 100,000 person-years (Ma et al., 2014). The progression of this disease is insidious. It is clinically characterized by static tremor, hypokinesia, muscle rigidity, and abnormal gait and posture (Schapira, 2006; Ma et al., 2014). To date, the etiology of PD is unknown; it may be related to several factors such as age, environmental factors, genetic factors, and oxidative stress (Zhang et al., 2000). The prevalence of PD varies by geographic location and ethnicity (Gordon et al., 2013), and it has never been studied in the Hetian region located in the south of Xinjiang, China. This region has a continental arid climate (with long daylight hours, little rain, high temperatures, and dry climate throughout the year). This study was a large-scale epidemiological investigation in which we aimed to identify the factors related to and determine the prevalence of PD in Hetian, Xinjiang Uygur Autonomous Region, which has a unique geographical environment.

\section{SUBJECTS AND METHODS}

\section{Subjects}

Using a hierarchical random cluster sampling method, we randomly sampled population clusters from the Hetian, Yutian, Moyu, and Luopu, Cele, Mingfeng, Pishan counties in the Hetian Prefecture from November to December 2010. We extracted a sample size within the corresponding township number (town) for two-sample clusters; in each of the two-sample clusters, registered households ( $\geq 10$ years) with Uygur resident villagers aged $\geq 45$ years were selected yielding a total of 5932 cases. This population met Brainbank diagnosis of Parkinson's disease (Hughes et al., 1992). After mutual consultations, 88 individuals were enrolled in the case group and 88 (1:1) individuals were randomly selected for the control group; the control group was matched for gender, nationality, and age (difference less than 2 years), and no subject in this group had PD or any other extrapyramidal disease. 


\section{Methods}

A questionnaire about the factors related to PD was designed considering the causes and possible factors of $\mathrm{PD}$, which were previously identified. After repeated testing and modification by a panel of experts, the epidemiological survey was performed by medical professionals and postgraduates who were trained together. Prior to the start of the survey, the researchers introduced the survey contents to the participants, and written informed consents were obtained. The items of the questionnaire included: age, gender, nationality, education level, profession, years of education, smoking, drinking, exercise, social activities, height and weight, history of pesticide exposure, history of head injury, family history of PD, and consumption of water, tea, nuts, potatoes, and barbecued food. The following criteria were used for classification: 1) years of education: $<9$ years of compulsory education was classified as low education and 9 or more years of compulsory education as high education; 2) pesticide exposure: exposure for 1-2 months each year for more than 5 consecutive years was consider positive; 3) exercise: performance of activities such as walking, climbing, cycling, all kinds of ball games, and such general sports less than once a week was considered as "low" and more than once a week as "high"; 4) social activities: performance of general social activities such as dancing, chatting, and playing chess less than once a week was considered as "low", and more than once a week as "high"; 4) body mass index [BMI; calculated as weight (kg)/ height ${ }^{2}\left(\mathrm{~m}^{2}\right)$ ]: the BMI was divided into four levels (Zhou, 2006): low-weight BMI $(<18.5$ $\left.\mathrm{kg} / \mathrm{m}^{2}\right)$, normal BMI $\left(18.5-23.9 \mathrm{~kg} / \mathrm{m}^{2}\right)$, overweight BMI $\left(24.0-27.9 \mathrm{~kg} / \mathrm{m}^{2}\right)$, and obesity BMI $\left.\left(\geq 28.0 \mathrm{~kg} / \mathrm{m}^{2}\right) ; 5\right)$ family history of PD was established if immediate relatives within the last three generations had had this disease; 6 ) tea drinking: drinking at least 1 cup every day, with at least $100 \mathrm{~mL}$ per cup, was considered positive else it was considered as low consumption; 7) consumption of nuts: eating at least $50 \mathrm{~g}$ each time $<2$ times/week was defined as low consumption and $\geq 2$ times/week was defined as high consumption; 8 ) consumption of potatoes: eating at least $50 \mathrm{~g}$ each time $<2$ times/week was defined as low consumption and 2 or more times per week was defined as high consumption; 9) consumption of barbecued food: eating $\leq 1$ time/week was defined as low consumption and $>1$ time/week was defined as high consumption.

\section{Statistical analysis}

Two researchers used EpiData 3.1 to input data independently and analyzed the prevalence of PD among different age groups (45-100 ages) in Hetian, Xinjiang Uygur Autonomous Region. Statistical Package for the Social Sciences (SPSS) 19.0 was used for single-factor and multi-factor conditional logistic regression analysis to compute the maximum likelihood estimator of odds ratio (OR), 95\% confidence interval (95\%CI), and $\mathrm{P}$ values. $\mathrm{P}<0.05$ was considered to be statistically significant.

\section{RESULTS}

\section{Prevalence of PD and general characteristics in the study population}

For the 5932 people enrolled in the survey, the average age was $57.80 \pm 10.02$ years, 
and the respondents consisted of 3034 men $(51.15 \%)$ and 2898 women (48.85\%). The age distribution and prevalence of PD is shown in Table 1. From the epidemiological survey, we found that 88 patients had PD. We included 88 subjects in the control group by recruiting in a 1:1 manner from the local population. There were 51 men $(57.95 \%)$ and 37 women $(42.05 \%)$ in both the groups. The average age was $64.76 \pm 11.471$ years (range: $45-95$ years) in the PD group and $64.81 \pm 11.01$ years (range: $45-93$ years) in the control group.

\begin{tabular}{|c|c|c|c|c|c|c|c|c|c|}
\hline \multirow[t]{2}{*}{ Age (y) } & \multicolumn{3}{|r|}{ Male } & \multicolumn{3}{|r|}{ Female } & \multicolumn{3}{|r|}{ Total } \\
\hline & $\begin{array}{l}\text { Survey } \\
\text { number }\end{array}$ & $\begin{array}{l}\text { PD } \\
\text { cases }\end{array}$ & $\begin{array}{c}\text { Prevalence } \\
\text { [standard prevalence (\%)] }\end{array}$ & $\begin{array}{l}\text { Survey } \\
\text { number }\end{array}$ & $\begin{array}{c}\text { PD } \\
\text { cases }\end{array}$ & $\begin{array}{c}\text { Prevalence } \\
\text { [standard prevalence (\%)] }\end{array}$ & $\begin{array}{l}\text { Survey } \\
\text { number }\end{array}$ & $\begin{array}{l}\text { PD } \\
\text { cases }\end{array}$ & $\begin{array}{c}\text { Prevalence } \\
\text { [standard prevalence }(\%)]\end{array}$ \\
\hline $45-$ & 894 & 5 & $0.56(0.19)$ & 1118 & 6 & $0.54(0.18)$ & 2012 & 11 & $0.55(0.25)$ \\
\hline $55-$ & 1033 & 16 & $1.55(0.51)$ & 930 & 11 & $1.18(0.39)$ & 1963 & 27 & $1.38(0.37)$ \\
\hline $65-$ & 792 & 20 & $2.53(0.62)$ & 655 & 13 & $1.98(0.48)$ & 1447 & 33 & $2.28(0.42)$ \\
\hline $75-$ & 252 & 8 & $3.17(0.22)$ & 166 & 5 & $3.01(0.21)$ & 418 & 13 & $3.11(0.23)$ \\
\hline $85-$ & 49 & 2 & $4.08(0.05)$ & 19 & 1 & $5.26(0.06)$ & 68 & 3 & $4.41(0.05)$ \\
\hline $95-100$ & 14 & 0 & $0.00(0.00)$ & 10 & 1 & $10.00(0.04)$ & 24 & 1 & $4.17(0.00)$ \\
\hline Sum & 3034 & 51 & $1.68(1.59)$ & 2898 & 37 & $1.28(1.36)$ & 5932 & 88 & $1.48(1.32)$ \\
\hline
\end{tabular}

\section{Analysis of factors related to PD}

Exercise, social activities, and frequent consumption of nuts were protective factors for PD $(\mathrm{P}<0.05)$, while pesticide exposure, family history of $\mathrm{PD}$, and frequent consumption of barbecued foods were risk factors $(\mathrm{P}<0.05$; Table 2$)$. Multi-factor conditional logistic regression analysis showed that exercise and social activity are associated with a reduced risk for PD, and pesticide exposure and PD family history of PD can increase the risk of PD onset. Consumption of barbecued food and nuts showed no obvious correlation with PD incidence (Table 3).

\section{DISCUSSION}

\section{Prevalence of PD}

Due to the social and economic development, life and health quality have improved. With the increase in aging population worldwide, the prevalence of PD is increasing every year. In the US, the prevalence of PD is about $0.03 \%$ in the entire population (McNaught and Olanow, 2006), $0.1-0.2 \%$ in individuals aged 65 or more, and $0.4-0.5 \%$ among individuals aged $>85$ years (Rao et al., 2006). Zhang et al. (2005) reported the PD prevalence to be $1.07 \%$ $(95 \% \mathrm{CI}=0.96-1.19 \%)$ in the population of $>55$-year olds in China and $1.67 \%(95 \% \mathrm{CI}=1.49$ $1.87 \%$ ) in individual aged $\geq 65$ years. We standardized our study population according to the 1999 Chinese population age distribution. The nationwide number of $>55$-year-old patients having PD was about 1.72 million (Zhang et al., 2005).

The present study found that the total prevalence of PD in Hetian was $1.48 \%$, while the prevalence among individuals aged $45-54,55-64,65-74,75-84,85-94$, and $>95$ years were $0.55,1.38,2.28,3.11,4.41$, and $4.17 \%$, respectively. In $>55$ - and $>65$-year-old people, PD 
Table 2. Results of single-factor conditional logistic regression analysis.

\begin{tabular}{|c|c|c|c|c|c|c|c|c|}
\hline \multirow[t]{2}{*}{ Factors } & \multicolumn{2}{|c|}{ PD group $(\mathrm{N}=88)$} & \multicolumn{2}{|c|}{ Control group $(\mathrm{N}=88)$} & \multirow[t]{2}{*}{$\chi^{2}$} & \multirow[t]{2}{*}{$\mathrm{P}$} & \multirow[t]{2}{*}{ OR } & \multirow[t]{2}{*}{$95 \% \mathrm{CI}$} \\
\hline & Cases & $\%$ & Cases & $\%$ & & & & \\
\hline Profession & & & & & 0.36 & 0.95 & & \\
\hline Peasant & 73 & 82.95 & 72 & 81.82 & & & & \\
\hline Worker & 7 & 7.95 & 8 & 9.09 & & & & \\
\hline Civil servant & 5 & 5.68 & 4 & 4.55 & & & & \\
\hline Unit & 3 & 3.41 & 4 & 4.55 & & & & \\
\hline Civil servant & & & & & 2.10 & 0.15 & & \\
\hline Civil servant & 77 & 87.50 & 82 & 93.18 & & & & \\
\hline Higher education & 11 & 12.50 & 6 & 6.82 & & & & \\
\hline Exercise, social activity* & & & & & 17.59 & 0.00 & & \\
\hline$<1 /$ week & 53 & 60.23 & 20 & 22.73 & & & & \\
\hline$\geq 1 /$ week & 35 & 39.77 & 68 & 77.27 & & & 0.21 & $0.10-0.44$ \\
\hline History of head injury & & & & & 0.78 & 0.38 & & \\
\hline No & 84 & 95.45 & 87 & 98.86 & & & & \\
\hline Yes & 4 & 4.55 & 1 & 1.14 & & & & \\
\hline Pesticide exposure history* & & & & & 14.56 & 0.00 & & \\
\hline No & 20 & 22.73 & 51 & 57.95 & & & & \\
\hline Yes & 68 & 77.27 & 37 & 42.05 & & & 3.21 & $1.76-5.85$ \\
\hline Drinking water & & & & & 3.29 & 0.19 & & \\
\hline Tap water & 36 & 40.91 & 30 & 34.09 & & & & \\
\hline River water & 15 & 17.05 & 11 & 12.50 & & & & \\
\hline Well water & 37 & 42.05 & 47 & 53.41 & & & & \\
\hline Classification of BMI & & & & & 7.22 & 0.07 & & \\
\hline Underweight & 3 & 3.41 & 6 & 6.82 & & & & \\
\hline Normal & 51 & 57.95 & 39 & 44.32 & & & & \\
\hline Overweight & 27 & 30.68 & 26 & 29.55 & & & & \\
\hline Fat & 7 & 7.95 & 17 & 19.32 & & & & \\
\hline PD family history* & & & & & 3.98 & 0.04 & & \\
\hline No & 76 & 86.36 & 84 & 95.45 & & & & \\
\hline Yes & 12 & 13.64 & 4 & 4.55 & & & 3.67 & $1.02-13.14$ \\
\hline Drinking tea & & & & & 1.74 & 0.19 & & \\
\hline No & 13 & 14.77 & 7 & 7.95 & & & & \\
\hline Yes & 75 & 85.23 & 81 & 92.05 & & & & \\
\hline Nut* & & & & & 6.03 & 0.01 & & \\
\hline$<2 /$ week & 49 & 55.68 & 33 & 37.5 & & & & \\
\hline$\geq 2 /$ week & 39 & 44.32 & 55 & 62.5 & & & 0.43 & $0.22-0.84$ \\
\hline Potato & & & & & 0.44 & 0.51 & & \\
\hline$<2 /$ week & 34 & 38.64 & 38 & 43.18 & & & & \\
\hline$\geq 2 /$ week & 54 & 61.36 & 50 & 56.82 & & & & \\
\hline Barbecue* & & & & & 4.80 & 0.03 & & \\
\hline$\leq 1 /$ week & 60 & 68.18 & 71 & 80.68 & & & & \\
\hline$>1 /$ week & 28 & 31.82 & 16 & 18.18 & & & 2.50 & $1.10-5.68$ \\
\hline
\end{tabular}

$* \mathrm{P}<0.05$.

Table 3. Results of multi-factor conditional logistic regression analysis of variables associated with PD.

\begin{tabular}{|c|c|c|c|c|c|c|}
\hline Variable & Regression coefficient & SE & $\chi^{2}$ & $\mathrm{P}$ & OR & $95 \% \mathrm{CI}$ \\
\hline Exercise and social activity* & -1.60 & 0.44 & 13.60 & 0.00 & 0.20 & $0.09-0.47$ \\
\hline Pesticides* & 1.05 & 0.37 & 7.87 & 0.01 & 2.85 & $1.37-5.91$ \\
\hline PD family history* & 1.83 & 0.80 & 5.21 & 0.02 & 6.21 & $1.30-29.80$ \\
\hline Barbecue & -0.17 & 0.28 & 0.39 & 0.53 & 0.84 & $0.49-1.44$ \\
\hline Nut & -0.71 & 0.44 & 2.63 & 0.11 & 0.49 & $0.21-1.16$ \\
\hline
\end{tabular}

$* \mathrm{P}<0.05$.

prevalence was $1.96 \%$ (77/3920) and 2.56\% (50/1957), respectively. In Hetian, PD prevalence in Uyghurs aged $>55$ years was $1.98 \%$ and in those aged $>65$ years, it was $2.60 \%$. PD prevalence among Uyghur residents in the area increased with age; this finding agrees with most of the research conducted in China as well as abroad. The high prevalence of PD in the area may 
be related to the high average lifespan in the region, the increased elderly population compared to other regions, nationality, regional environment, living customs, and other factors.

\section{PD-related factors}

Numerous studies have found that age is closely related to PD incidence (Collier et al., 2007). Other factors, such as exposure to pesticides and heavy metals, drinking well water, occupation, educational level, gender, smoking history, physical exercise, are related to the development of PD (Collier et al., 2007; Pallone, 2007).

The study by Goldman et al. (2005) showed that engaging in agricultural labor increased the risk of PD, while an occupation in the service industry was associated with a relatively lower risk of PD. A case-control study conducted in New York found that PD risk increases with education level (Marder et al., 1998). In contrast, Taylor et al. (1999) showed that a high education level was protective factor in PD. Our study found no obvious correlation of occupation and educational level with the incidence of PD. This may be because of the influence of regional characteristics, occupational exposure, and health status. Because most of the people in this region were farmers and the professional distribution was manual labor, further research is needed to clarify the association between PD incidence and occupation.

There was significant difference between the case and control groups with respect to pesticide exposure $(\mathrm{P}<0.05)$. Compared with no pesticide exposure, long-term exposure to pesticides increased the risk of PD by 3.21 times. Controlling for other confounding factors, pesticide exposure was identified as a risk factor for PD. This is in line with the results reported by Kamel (2013) and other investigators.

Previous studies have found that people who engage in physical activity or exercise have a lower risk of PD and later onset age than the general population (Chen et al., 2005). Patients also can improve the symptoms of PD through appropriate exercise (Crizzle and Newhouse, 2006). Our study showed that the risk of PD in people who participated in exercise and social activities ( $\geq 1$ time/week) was 0.21 times lower than that in those who did not exercise often $(95 \% \mathrm{CI}=0.10-0.44, \mathrm{P}<0.05)$. These results suggest that exercise and social activities are protective against PD. Multi-factor conditional logistic regression analysis also showed that participation in sports (exercise) and social activities affords protection from PD.

A study by Tanner et al. (1999) found that genetic factors are the most important reason for early-onset PD; however, patients in whom PD presented after the age of 50 did not have obvious genetic characteristics. Further, a family history of PD increases the risk of PD by 3.67 times (Zorzon et al., 2002). In this study, the case and control groups significantly differed with respect to family history of $\mathrm{PD}(\mathrm{P}<0.05)$. Further, multi-factor conditional logistic regression analysis showed that family history of PD was a risk factor for PD development.

Galanaud (2005) found that smoking was negatively correlated with the incidence of PD. Alves et al. (2004) found that smoking in patients already diagnosed with PD had no protective effect. In our study, influenced by folk habits, few of the subjects smoked. Therefore, we did not investigate the correlation between smoking and PD.

Latest research (Mandel et al., 2008) shows that the risk of PD is reduced by $28-80 \%$ in long-term tea drinkers. However, a case-control analysis revealed that drinking tea is a risk factor for PD (Preux et al., 2000). Our study did not show an obvious correlation between tea drinking and PD. It may be because most Uyghurs drink tea frequently, leading to no obvious difference in the Uyghur residents in this aspect. Uyghurs like to eat nuts such as BaDanMu, 
which is rich in protein, fat, minerals, vitamins, trace elements, and dietary fiber. Nuts can affect growth, eliminate free radicals, delay senescence, and inhibit DA neurons damage. The Maillard reaction, which occurs during the process of grilling, results in the formation of products which are transformed to advanced glycosylation end-products (AGEs) in the body. Accumulation of AGEs in the body over a long period can lead to Alzheimer's disease, PD, and other neurological diseases (Takeuchi and Makita, 2001). Studies examining the relationship between consumption of nuts and barbecued food and PD are limited. In this study, considering the characteristics of the Xinjiang region, we investigated the correlation between the residents' habit of eating nuts and barbecued food and PD. Our results show that people who eat nuts frequently are 0.43 times less likely to develop PD than those who do not $(\mathrm{P}<0.05)$. However, when controlling for other confounding factors in multiple factor analysis, we found no obvious association. Eating barbecued food more than once a week increased PD risk by 2.50 times, compared to eating $\leq 1$ times/week. However, again, multi-factor conditional logistic regression analysis did not show significant correlation between PD and consumption of barbecued food $(\mathrm{P}>0.05)$.

PD is a result of multiple factors involving environmental and genetic interaction (Kyrozis et al., 2013). This epidemiological investigation studied the prevalence of and factors related to PD in the area of Hetian, Xinjiang Uygur Autonomous Region. We showed that participation in exercise and social activities and eating nuts frequently were protective factors against PD. The risk factors were a family history of PD and long-term pesticide exposure; a possible risk factor was eating barbecued food. Based on our results, feasible measures should be implemented to prevent and control the occurrence of PD in Hetian, Xinjiang region.

\section{ACKNOWLEDGMENTS}

Research supported by grants from the National Natural Science Foundation of China (\#81460178), and the Assisting Research Project of Science and Technology for Xinjiang (\#201591160).

\section{REFERENCES}

Alves G, Kurz M, Lie SA and Larsen JP (2004). Cigarette smoking in Parkinson's disease: Influence on disease progression. Mov. Disord. 19: 20.

Chen H, Zhang SM, Schwarzschild MA, Hernán MA, et al. (2005). Physical activity and the risk of Parkinson disease. Neurology 64: 664-669.

Collier TJ, Lipton J, Daley BF, Palfi S, et al. (2007). Aging-related changes in the nigrostriatal dopamine system and the response to MPTP in non-human primates: diminished compensatory mechanisms as a prelude to Parkinsonism. Neurobiol. Dis. 26: 56-65.

Crizzle AM and Newhouse LJ (2006). Is physical exercise beneficial for persons with Parkinson's disease. Clin. J. Sport Med. 16: 422-425.

Galanaud JP, Elbaz A, Clavel J, Vidal JS, et al. (2005). Cigarette smoking and Parkinson's disease: a case-control study in a population characterized by a high prevalence of pesticide exposure. Mov. Disord. 20: 181-189.

Goldman SM, Tanner CM, Olanow CW, Watts RL, et al. (2005). Occupation and parkinsonism in three movement disorders clinics. Neurology 65: 1430-1435.

Gordon PH, Zhao H, Bartley D, Sims LJ, et al. (2013). Prevalence of Parkinson disease among the Navajo: a preliminary examination. J. Parkinsons Dis. 3: 193-198.

Hughes AJ, Daniel SE, Kilford L, and Lees AJ (1992). Accuracy of clinical diagnosis of idiopathic Parkinson's disease: a clinicopathological study of 100 cases. J. Neurol. Neurosurg. Psychiatry 55: 181-184. 
Kamel F (2013). Epidemiology. Paths from pesticides to Parkinson's. Science 341: 722-723.

Kyrozis A, Ghika A, Stathopoulos P, Vassilopoulos D, et al. (2013). Dietary and lifestyle variables in relation to incidence of Parkinson's disease in Greece. Eur. J. Epidemiol. 28: 67-77.

Ma CL, Su L, Xie JJ, Long JX, et al. (2014). The prevalence and incidence of Parkinson's disease in China: a systematic review and meta-analysis. J. Neural Transm. 121: 123-134.

Mandel SA, Amit T, Kalfon L, Reznichenko L, et al. (2008). Targeting multiple neurodegenerative diseases etiologies with multimodal-acting green tea catechins. Nutrition 138: 1578S-1583S.

Marder K, Logroscino G, Alfaro B, Mejia H, et al. (1998). Environmental risk factors of Parkinson's disease in an urban multiethnic community. Neurology 50: 279-282.

McNaught KS and Olanow CW (2006). Protein aggregation in the pathogenesis of familial and sporadic Parkinson's disease. Neurobiol. Aging 27: 530-545.

Pallone JA (2007). Introduction to Parkinson's disease. Dis. Mon. 53:195-199.

Preux PM, Condet A, Anglade C, Druet-Cabanac M, et al. (2000). Parkinson's disease and environmental factors. Matched case-control study in the Limousin region, France. Neuroepidemiology 19: 33-37.

Rao SS, Hofmann LA and Shakil A (2006). Parkinson's disease: diagnosis and treatment. Am. Fam. Phys. 74: 2046-2054.

Schapira AH (2006). Etiology of Parkinson's disease. Neurology 66: S10-S23.

Takeuchi M and Makita Z (2001). Alternative routes for the formation of immunochemically distinct advanced glycation end-products in vivo. Curr. Mol. Med. 1: 305-315.

Tanner CM, Ottman R, Goldman SM, Ellenberg J, et al. (1999). Parkinson disease in twins: an etiologic study. JAMA 281: 341-346.

Taylor CA, Saint-Hilaire MH, Cupples LA, Thomas CA, et al. (1999). Environmental, medical, and family history risk factors for Parkinson's disease: a New England based case control study. Am. J. Med. Genet. 88: 742-749.

Zhang Y, Dawson VL and Dawson TM (2000). Oxidative stress and genetics in the pathogenesis of Parkinson's disease. Neurobiol. Dis. 7: 240-250.

Zhang ZX, Roman GC, Hong Z, Wu CB, et al. (2005). Parkinson's disease in China: prevalence in Beijing, Xi'an, and Shanghai. Lancet 365: 595-597.

Zhou BF (2006). Predictive values of body mass index and waist circumference to risk factors of related diseases in Chinese adult population. Chin. J. Epidemiol. 39: 408-409.

Zorzon M, Capus L, Pellegrino A, Cazzato G, et al. (2002). Familial and environmental risk factors in Parkinson's disease: a case-control study in north-east Italy. Acta Neurol. Scand. 105: 77-82. 